Of the excessive use of tobacco, such as I have mentioned, it is impossible to speak in too strong terms of condemnation, whether in regard to its effects upon the moral or physical man. When thus abused, it is productive of formidable symptoms, and may unquestionably lead to premature decay, if not to death. There is, in fact, no more pitiable object than the inveterate smoker, the man who, $t$, use a common phrase, "is never without a pipe in his mouth," especially if the habit has been acquired in early boyhood. Tremulous, emaciated, emasculate his face the colour of a faded Palmer's candle, his brenth foetid, his mind enfeebled and irresolute, such a being is useless to others, and except when under the influence of his pipe, a burden to himself. But such an object is comparatively rare, and should no more be considered as the normal type of a tobacco-smoker than the bloated, staggering, Bright's-kidneyed wretch seen at the door of a London gin-shop should be held up as a bugbear to scare a man out of his after-dinner glass of honest port-wine. These are examples, each of their kind, of insensate abuse, and not of temperate enjoyment. The moderate smoker is, I believe, cceteris paribus, as healthy an individual as any other, and the worst that can be said of him is, that he indulges in a superfluous luxury, and that the money so expended might be better employed. The same may be said of scented soap and watch-chains.

But clear as it is that tobacco smoked to excess is injurious to health, cannot it be shown that there are circumstances and conditions of life in which the practice is not only harmless but even salutary? Ask those heroic men who have retnrned from the ice-bound regions, too probably the grave of Franklin and his messmates-ask the late denizens of the Crimean trenches, and will they not all avow that one great solace and preservative under their incredible hardships was their pipe of tobacco?

It is apparent from these remarks that $I$ do not join in the well-meant but unreasonable movement which would expunge tobacco from use because it is frequently abused ; still I would most strenuously exclaim against such abuse as most destructive to the health, not only of the individual, but of his progeny and it is in the hope of deterring those who are moderate from the acquisition of habits of immorlerate and pernicious indulgence that the following portraiture of the symptoms of tobacco poisoning is drawn.

I may premise that I do not consider the effects of smoking tobacco to depend upon inhalation of its fumes into the liungs, as might prima facie be imagined. Any smoker will tell us that the smoke does not descend the windpipe, but merely circulates in the mouth and pharynx, and is then expelled. The act of smoking is suction, in fact, not inhalation. The effects of smoking are, I believe, chiefly due to the impregnation of the saliva with the essential oil, and the swallowing of this into the stomach. In the uninitiated this, it is well known, produces nausea, vomiting, cold sweats, and severe syncopal prostration; but after a time the system becomes so far habituated to the practice of smoking, that these symptoms are not induced; and if when this point is reached the practice is in dzllged in moderately, no further ill effects follow in the great majority of cases. Supposing, however, the habit to become more intense, and the moderate smoker of one or two pipes or cigars a day consumes his eight or ten, or even passes all his waking hours with a pipe in his mouth, then a train of symptoms ensues which indicate chronic nicotic poisoning, and which, if they do not actually destroy life, seriously impair the physical and mental vigour.

The earliest signs of the injurious effects of smoking are, as might be expected, manifested in the digestive system. The inveterate smoker is a victim to heartburn, acidity, and flatulence, relieved for a time by food, but returning as digestion proceeds. The appetite becomes capricious, and ultimately feeble; the bowels, though regular, are not relieved of healthy evacuations; the secretions, to use a current phrase, are all wrong; the frame wastes, and the skin assumes a dirty tallowy hue; the muscular energy diminishes, and the heart becomes irritable, palpitating painfully at irregular intervals; the sexual powers speedily begin to fail; indeed it is a general remark that great smokers are less than commonly open to amatory temptations; complete impotence is the result in extreme cases. The mental faculties participate in the general debility; the mind is vacillating, and incapable of sustained exertion, and ultimately in some instances symptoms occur which indicate cerebral softening, such as loss of memory, tendency to causeless weeping, partial paralysis, \&c.

The exact amount of indulgence which is required to induce this deplorable state cannot be specified, as much depends npon the mode of life of the individual in other respects. The earlier in life smoking becomes a habit, the sooner will these effects declare themselves; and sad indeed is the prospect for the cadaverous collar-strangled boys who in the present day throng the streets, the pipe or cigar ever in their mouths. Again, the man who is much in the open air may indulge with impunity, when the sedentary man wonld be injured. Every individual may, however, judge for himself whether he is exceeding the limits of prudence; if heartburn and flatulence follow smoking, either immediately or as a prevailing dyspeptic symptom, the smoker should take warning.

A question has been mooted, whether excessive smoking is a cause of insanity. It may lead to mental feebleness and incapacity, but that it cannot be considered as a cause of aberration of mind is, I think, sufficiently shown by the fact mentioned by Mr. Watson, that insanity is most prevalent amongst females, while smoking is quite exceptional in the sex. With regard to the propriety of allowing lunatics to indulge moderately in smoking, I may state that some considerable experience has convinced me that, under proper supervision, smoking is in no way prejudicial; on the contrary, Thave fancied that it is rather beneficial than otherwise, and that to deprive the deranged patient of his habitual solace would be needlessly to vex his disturbed mind.

I must apologise for the length of these remarks; the importance of placing the subject before the public in its true bearing must be my excuse. My motive has been truly " $e x$ fumo dare lucem," and I trust that in some measure I may have accomplished my object.

Norwich, Feb. 1856 I am, Sir, yours, \&c.

W. H. RaNkiNG, M.D.

\section{FIFTY YEARS' EXPERIENCE.}

[LETTER FROM JOHN HIGGINBOTTOM, ESQ., F.R.S.]

$$
\text { To the Editor of TrE LANCET. }
$$

SIR, - I have been much gratified with Mr. Solly's letters on the tobaceo question, and most heartily concur in every word he has written. I consider the investigation of the subject of vital importance to the welfare of every Englishman. I congratulate Mr. Solly on having roused the profession and the public from their narcotic dreams and slumbers.

It is now half a century since I first observed the pernicious effects of smoking tobacco, but more especially for the last twenty years, during which period the evil has greatly increased; indeed, so strong were my convictions that smoking was a very ordinary cause of paralysis, apoplexy, insanity, and dyspepsia in all its Protean forms, that I pubiished a pamphlet, and a number of papers in a popular form in a local journal, and also delivered public lectures in Nottingham on the subject; feeling it as much the duty of a medical man to prevent as to cure disease.

The decision [ have come to, after fifty years' most extensive and varied practice in my profession is, that tobacco in every form has no redeeming property whatever; and at the present time it is a main canse in ruining our young men, pauperising the working men, and also rendering comparatively useless the best endeavours of ministers of religion. I cannot conclude these remarks better than in the words of Mr. Solly, at the termination of his first excellent letter:- "So strongly do I feel its importance, that I believe, if the habit of smoking in England advances as it has done during the last ten or twelve years, that the English character will lose that combination of energy and solidity which has hitherto distinguished it, and that England will sink in the scale of nations."

I am, Sir, yours obediently,

Nottingham, Feb. 19th, 1857. JoHN HrGGINBotTom, F.R.S.

\section{DISEASES PRODUCED BY SMOKING.}

[LETTER FROM SAMUEL BOOTH, HSQ, L. S.A.]

\section{To the Editor of THE LANCET.}

SIR,-It has given me great pleasure to know that you have opened the pages of your excellent journal to the discussion of the important question, "Is smoking injuriaus?" I am of opinion, with Mr. Solly, "that THE LANCEr has done maluch to. relieve suffering humanity, but never so mueh good as the present devotion of its pages to this important question, upon which the happiness or misery of thousands depends."

I had been a smoker for twelve years, and can say that I 